\title{
PANDEMIA E DECISÃO DA PESSOA IDOSA SOBRE VIVER E MORRER
}

Yeda Aparecida de Oliveira Duarte'

ORCID: 0000-0003-3933-2179

Luciana Mitsue Sakano Niwa'

ORCID: 0000-0002-9342-7454

Pamella Cristina de Carvalho Lucas'

ORCID: 0000-0003-3661-3290

Aline de Sousa Meira" ORCID:0000-0002-5272-1788

Shirley da Rocha Afonso"' ORCID:0000-003-1824-0451

'Universidade de São Paulo. São Paulo, São Paulo, Brasil.

"Universidade de São Paulo. Ribeirão Preto, São Paulo, Brasil.

II'Centro Paula Souza.

São Paulo, São Paulo, Brasil.

Autor Correspondente: Yeda Aparecida de Oliveira Duarte E-mail:yedausp@gmail.com

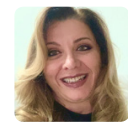

Como citar:

Duarte YAO, Niwa LMS, Lucas PCC, Meira AS, Afonso SR. Pandemia e decisão da pessoa idosa sobre viver e morrer, In: Santana RF (Org.). Enfermagem gerontologica no cuidado do idoso em tempos da COVID 19. 2.ed.rev. Brasilia, DF: Editora ABEn; 2020. p 25-29.

(Serie Enfermagem e Pandemias, 2). https://doi.org/10.51234/aben.20.e02.c04

\section{INTRODUÇÃO}

A palavra autonomia vem do grego "autos", próprio, e "nomos", regra, ou lei. Segundo o Dicionário Aurélio da Língua Portuguesa, autonomia é "aptidão ou competência para gerir sua própria vida, valendo-se dos seus próprios meios, vontade e/ou princípios. A pessoa autônoma diante de sua liberdade age conforme suas escolhas, sem nenhuma influência. Respeitar a autonomia é não violar os seus direitos, é reconhecer que cada um tem suas escolhas, suas crenças, seus valores e sua individualidade. Nesse contexto a autonomia está relacionada ao princípio da dignidade humana, reconhecendo o homem como um sujeito de direitos ${ }^{(1)}$ (2).

O hospital costuma ser um ambiente cujo foco é a resolutividade da doença, onde o modelo biomédico é altamente predominante. A urgência pelo atendimento, as ações mecanizadas e a hierarquização do sistema hospitalar cria uma barreira entre o indivíduo e o profissional de saúde, tornando esse local um ambiente agressor. Em situações "normais", o ambiente hospitalar já tem a tendência de ser um fator contribuinte para a perda da autonomia do indivíduo idoso hospitalizado ${ }^{(5)}$.

E o que muda no contexto da pandemia? Seria possível pensar que a autonomia da pessoa idosa poderia ser ainda mais comprometida? Seria possível crer que critérios etários poderiam ser estabelecidos para determinar escolhas entre os que vivem e morrem em ambientes com materiais e equipamentos escassos? Nesse momento de pandemia, no entanto, vivenciamos tristes situações verbalizadas por diferentes pessoas e autoridades verbalizando "critérios" para priorização de determinados pacientes nas Unidades de Tratamento Intensivo e na divisão de recursos escassos. Seria digno estabelecer o critério etário para tais escolhas?

A Política Nacional de Saúde da Pessoa Idosa traz como finalidade primordial a recuperação, manutenção e promoção da autonomia e independência do indivíduo idoso(4). 
Autonomia é um termo encontrado dentro dos princípios bioéticos, que são eles, a beneficência, não maleficência, autonomia e justiça.

\section{OBJETIVO}

Refletir sobre o direito da pessoa idosa decidir sobre sua própria vida/morte se estiver contaminada pelo COVID-19.

\section{MÉTODOS}

Trata-se de um texto teórico-reflexivo sobre o direito da pessoa idosa decidir sobre sua própria vida/ morte se estiver contaminada pelo COVID-19. As reflexões foram pautadas em publicações internacionais e nacionais relacionados ao tema, às diretrizes antecipadas de vontade, ao testamento vital, à autonomia da pessoa idosa e vivencias das autoras.

\section{RESULTADOS}

A Política Nacional de Saúde da Pessoa Idosa traz como finalidade primordial a recuperação, manutenção e promoção da autonomia e independência da pessoa idosa ${ }^{(4)}$. Autonomia é um termo definido em diferentes contextos, incluindo o dos princípios bioéticos, que são a beneficência, a não maleficência, a autonomia e a justiça.

Discussões bioéticas no mundo acadêmico tiveram inicio na década de 70 com o bioquímico norte-americano Van Rensselaer Potter, que apontava como desafio para a sociedade moderna o aproveitamento das expertises dos especialistas a favor da promoção da sobrevivência humana categorizando os problemas considerados fundamentais: população, paz, poluição, pobreza, política e progresso. Segundo o autor, foca-se apenas no progresso, dando-se pouca atenção aos outros problemas o que coloca em risco o futuro da humanidade. O termo bioética foi, no entanto, utilizado pela primeira vez pelo teólogo alemão, Fritz Jahr, em 1927: "Respeite todo ser vivo como princípio e fim em si mesmo e trate-o, se possível, enquanto tal."(2)

Segundo Beuchamp e Childress (2002), a pessoa autônoma tem total liberdade para escolher o que é melhor para si e tomar suas próprias decisões. O indivíduo autônomo, continuam os autores, possuem duas condições essenciais, liberdade, livre de influências externas e a capacidade de agir livremente ${ }^{(2)}$.

A Autonomia como valor humano pode ser impactada com o processo de hospitalização e, mais ainda, nesse momento que estamos vivenciando da pandemia COVID-19. Todos os direitos dos pacientes devem ser respeitados desde o momento de sua admissão até sua alta hospitalar. Preservar sua autonomia é defender sua integridade física e moral a qualquer custo.

Segundo o Estatuto do Idoso ${ }^{(3)}$, em seu Art. 20, "O idoso goza de todos os direitos fundamentais inerentes à pessoa humana, sem prejuízo da proteção integral de que trata esta Lei, assegurando-se lhe, por lei ou por outros meios, todas as oportunidades e facilidades, para preservação de sua saúde física e mental e seu aperfeiçoamento moral, intelectual, espiritual e social, em condições de liberdade e dignidade". Dessa forma, é dever do profissional de saúde propor ações que busquem a qualidade de vida do idoso, principalmente para aquele que não é capaz de agir livremente, respeitando e preservando sua dignidade.

A ciência moderna, mesmo antes da pandemia, já mostrava interesse no jovem, em seu futuro promissor e no seu poder de produção. O envelhecimento e a morte não eram, até então, pauta nas grandes mídias e o corpo marcado por experiência e anos vividos não era tão valorizado, ao contrário, era trazido como um problema econômico e social reforçando preconceitos. Esse preconceito muitas vezes era revelado dentro das instituições de saúde quando os profissionais desconsideravam a capacidade do idoso em decidir sobre seu tratamento ou sobre as intervenções a que seria submetido. Ao falar do tratamento, por exemplo, muitas vezes os profissionais dirigiam-se aos familiares ou ofereciam informações superficiais e não claras ao idoso, 
subestimando sua capacidade de compreensão e, assim, desrespeitar sua autonomia, e desconsiderando-o como sujeito do seu processo de saúde e doença ${ }^{(5)}(7)$.

A situação de estar "internado" em um hospital, independente do contexto da pandemia, já é uma situação de fragilidade, além da doença que o levou a procurar o serviço de saúde, a tecnologia, burocracia e rotinas administrativas restringem a pessoa idosa em suas atividades básicas. A priorização pelos procedimentos, protocolos institucionais, necessários para a organização da assistência trazem para a pessoa idosa um cenário completamente desconhecido e podem dificultar seu poder de tomada de decisão ${ }^{(5)}$.

Além da barreira das ações mecanizadas e administrativas do hospital, há o paternalismo profissional, que com a desculpa de beneficiar o paciente tiram-lhe o direito de tomada de decisão, colocando em risco a sua dignidade ${ }^{(1)}$. Neste contexto a responsabilidade do cuidado fica centrada apenas nos profissionais de saúde que decidem, cuidam, orientam tomam as decisões, desconsiderando as capacidades da pessoa idosa e de sua família(2). Cuidar é perceber o outro, como ser único, que possui virtudes, família, história e escoIhas. Qualquer coisa que não considere isso, não é cuidar, muito menos cuidado humanizado. No ambiente hospitalar ocorre uma despersonalização da pessoa idosa a partir do momento que o direito a tomada de decisão é dado a outros.

Alterações das funções intelectuais afetam a autonomia da pessoa idosa. O grande desafio para os profissionais de saúde é cuidar do idoso nessas condições, respeitando e reconstruindo o seu poder decisão que agora não está mais em suas mãos. A preservação da individualidade no ambiente hospitalar deve ser ferramenta primordial de quem cuida, principalmente para aquele que está comprometido e não consegue mais fazer suas próprias escolhas, dentro deste cenário é preciso preservar e garantir a dignidade humana. O envolvimento com os familiares, nesse momento, é indispensável, reconhecendo quem seria a pessoa mais próxima do idoso, aquela que o conhece melhor, que seria capaz de indicar suas escolhas e vontades.

\section{Diretivas antecipadas de vontade, idosos e COVID-19}

As Diretivas Antecipadas de Vontade constituem um guarda-chuva de documentos, feitos por pessoas capazes, sem diagnóstico prévio, que expressarão sua vontade para quando e se esse um diagnóstico de doença sem possibilidade terapêutica de cura ocorrer. Trata-se de um exercício de futurologia que pode nunca ocorrer. Um dos documentos que faz parte das Diretivas é o Testamento Vital. As diretivas retratam as vontades prévias da pessoa no que diz respeito aos cuidados de saúde, ou seja, o que é desejado ou não em relação ao seu tratamento em uma situação em que não poderá, por motivo de doença, responder espontaneamente qual seria sua vontade.

As diretivas antecipadas de vontade aumentam o empoderamento e reforçam o direito a autonomia, permitindo a recusa de um tratamento indesejado, o respeito das vontades, valores e princípios da pessoa quando ele não pode mais se expressar livremente e tomar decisões. Qualquer intervenção requer um consentimento livre esclarecido, na qual o profissional de saúde tem o dever de informar de forma clara e acessível todas as informações inerentes ao procedimento e tratamento para que o paciente tenha ferramentas para decidir com consciência.

Para Beuchamps e Childress (2002) o consentimento informado deve conter cinco elementos estruturais: competência, comunicação, compreensão, voluntariedade e consentimento. O documento exige que o leitor compreenda as informações que estão descritas e que a partir delas haja voluntariedade, decisão e autorização do plano escolhido. Dessa forma o consentimento livre esclarecido cumprirá o seu papel. Assim o testamento vital se trata de um consentimento prospectivo, ou seja, as decisões tomadas dizem respeito ao futuro(2).

É importante compreender que as Diretivas antecipadas de vontade (DAV) e o Testamento Vital estão interligados. Em síntese tratam de registrar o desejo da pessoa em relação a própria vida quando essa não pudesse mais expressar isso. Estamos vivenciando uma pandemia cujo Coronavírus traz risco à vida e isso pode ocorrer de forma muito rápida onde as pessoas podem não ter tempo de expressar sua vontade ${ }^{(6)}$. 
Nesse momento gostaríamos de ressaltar que algumas pessoas, idosas ou não, podem ter feito suas DAV anteriormente ao COVID-19. Essa decisão valeria nesse momento? O Indivíduo pode mudar de idéia?

Por isso é importante ressaltar que o profissional de saúde pode necessitar fazer escolhas pela incapacidade de assistir totalmente a demanda apresentada. Se chegarmos a essa situação caótica, as pessoas idosas serão preteridas em relação aos mais jovens mesmo manifestando seu desejo de continuar a viver, isso pode ter consequências éticas e morais vindouras nas famílias e profissionais de saúde, e por isso, merecem reflexão profunda. ${ }^{(6)}$

O Testamento vital é um documento que pode ser feito por qualquer pessoa $\geq 18$ anos onde será descrito a maneira com ela quer ou não quer ser cuidada quando tiver uma doença irreversível, grave e incurável. $\mathrm{O}$ Coronavirus não é uma doença crônica, terminal, sem tratamento. Trata-se de uma doença aguda, potencialmente reversível, com amplo tratamento e medidas de conforto sendo possível ser revertida. Assim, a covid-19 não é um cenário de aplicação do testamento vital pois não é uma doença que pode ser enquadrada na situação de terminalidade, irreversibilidade e incurabilidade ${ }^{(6)}$.

Por isso, caso a pessoa idosa já fez um testamento vital, ele não se aplica ao covid-19, caso ela venha a se contaminar. Pois, o Testamento vital foi feito anteriormente à pandemia e, possivelmente por outros motivos. Ela deve receber todos os aparatos e suportes de tratamento possíveis para auxiliá-lo e reverter a doença. $\mathrm{A}$ manifestação de vontade expressa anteriormente só é válida para uma situação de final de vida que não é, necessariamente, a situação apresentada pelo covid-19. Mesmo que a situação seja muito grave e irreversível, o que deve valer, é o que a pessoa expressar, como vontade, naquele momento pois o testamento vital pode ser mudado a qualquer momento. Se ele existir, ele pode ser modificado nesse momento, para essa situação que se caracteriza como aguda. ${ }^{(6)}$

É importante ressaltar também que atualmente, toda pessoa com idade $\geq 18$ anos tem o direito de recusar terapêuticas. Assim, pode ocorrer que algumas pessoas, idosas ou não, optem por não utilizarem um respirador, quando esses não estiverem disponíveis para todos, como gestos altruístas, mas essa não é a regra, de forma alguma. Esse não é um pedido que possa ser feito à ninguém, em hipótese alguma, mesmo havendo um número insuficiente de equipamentos para atender a todos os que deles necessitam. Da mesma forma, não é possível partir do pressuposto, que uma determinada pessoa, por ter determinada idade, terá menos direito de uso do equipamento ou menos chance de recuperação por ter idade mais avançada. Esse pensamento é absolutamente discriminatório e inconstitucional. Critérios de escolha com base na idade cronológica são refutados em qualquer lugar do mundo. ${ }^{(6)}$

Infelizmente, frente ao cenário caótico que vivenciamos, critérios de escolha poderão ocorrer. Estamos em uma situação nova, com menos recursos do que necessitamos, mas, mesmo assim, de forma alguma, a idade pode ser o critério a ser considerado, nem mesmo para desempate quando outros critérios forem utilizados. Os protocolos utilizados devem ser absolutamente técnicos. Em caso de empate, se necessário for, a opção pode ser a randomização, que, em não havendo outra forma, talvez seja mais justa do que optar simplesmente pelo critério etário. O correto, no entanto, é não faltar recursos para ninguém e essa é uma responsabilidade do estado. ${ }^{(6)}$

No exterior, uma forma de lidar com essa situação tem sido solicitar às pessoas que manifestem sua vontade de forma a tirar essa carga dos profissionais de saúde e das instituições. Em nosso meio isso não ocorre. Há notícias de um maior abandono terapêutico com as pessoas idosas e um encaminhamento dessas para cuidados paliativos por falta de recursos tentando justificar o injustificável ${ }^{(6)}$.

Esse cenário caótico não deve, em nenhum momento, ser naturalizado pois estaríamos reforçando preconceito contra as pessoas idosas ainda muito arraigado à nossa sociedade. É necessário raciocinar sobre os preconceitos e tirar a naturalização que tendemos a fazer sobre eles. ${ }^{(6)}$.

Se renunciarmos à proteção da pessoa idosa nesse momento, estaremos renunciando à proteção dos que hoje são mais jovens no futuro e, em última instancia, do próprio futuro. Pois, uma sociedade que não valoriza seu passado, não constrói o seu futuro. 


\section{CONSIDERAÇÕES FINAIS}

O cuidado vai além de cumprir rotinas, prescrições e tarefas. Cuidar é compreender que cada um tem sua individualidade, seu estilo de vida, suas crenças, valores e cada pessoa envelhece de uma forma, portando não se pode generalizar a assistência do cuidado ao idoso e, muito menos, negar essa assistência por um critério etário.

É preciso preservar e reforçar as potencialidades do idoso, para isso é preciso identificar precocemente quais as suas disfunções físicas e sociais, para que assim seja possível implementar estratégias de saúde que minimizem os impactos da hospitalização.

O critério etário não pode ser utilizado para definir o tratamento que a pessoa idosa irá ou não receber em relação ao covid-19. O Sistema de Saúde em colapso deve ser uma prioridade do Estado e as pessoas idosas não podem, em nenhum momento, serem penalizadas por uma gestão ineficiente.

O enfermeiro em sua prática profissional encontra cotidianamente questões éticas ao lidar com o idoso e sua família, respeitar suas crenças, seus valores e sua autonomia e preservar sua dignidade tornam-se um dever não só para os profissionais de saúde, mas para todo cidadão.

\section{AGRADECIMENTO}

\section{Ao Departamento Científico de Enfermagem Gerontológica da ABEn Nacional.}

\section{REFERÊNCIAS}

1. Aghich, GJ. Dependência e autonomia na velhice. Um modelo ético para o cuidado de longo prazo. São Paulo: Loyola., 2008; 5:237-304.

2. Beauchamp TL, Childress JF. Princípios de ética biomedical. Edição 1. São Paulo: Loyola; 2002; 3:137-07.

3. BRASIL. Presidência da República. Dispõe sobre o Estatuto do Idoso e dá outras providências. Lei n¹0.741, de 1 de outubro de 2003.

4. BRASIL. Ministério da Saúde. Aprova a Política Nacional de Saúde da Pessoa Idosa. Portaria n 2.528, 19 de outubro de 2006. Diário Oficial da União. 2006.

5. Cunha JXP, Oliveira JB, Nery VAS, Sena ELS, Boery RNSO, Yarid SD. Autonomia do idoso e suas implicações éticas na assistência de enfermagem. Saúde debate. 2012; 36(95): 657-64.

6. Dadalto, L. Eu decido meu destino: Testamento vital. Disponível em: https://youtu.be/q5KmdowGIAk. 2020.

7. Moreira, JO. Mudanças na percepção sobre o processo de envelhecimento: reflexões preliminares. Psicologia: Teoria e Pesquisa. 2012; 28: 451-456. 